of $L, M$ and $T$ ? Nothing in this book is more reasonable than the concluding paragraph of Rücker's paper, namely, that by not suppressing the secondary fundamental units such as $\mu$ and $K$,

"I think that the symbols are thus made to express the limits of our knowledge and ignorance on the subject more exactly than if we arbitrarily assume that some one of the quantities involved is an abstract number."

The Giorgi suggestion to regard one of the electromagnetic concepts as fundamental is in keeping with this. If permeability be thus adopted as fundamental, there can be no question of its dimensions. The dimensions of length, mass, time and permeability are then $L, M, T$ and ' $\mu$ ', and just as certain values of the first three (C.G.S. or M.K.S.) are taken as units, so in the Giorgi system, unit permeability is $10^{7}$ times that of space. All the electromagnetic concepts can be expressed dimensionally in terms of $L, M, T$ and ' $\mu$ ' without ambiguity and without making arbitrary and unjustifiable assumptions. If, in the future, Nature divulges some secret whereby the limits of our knowledge are extended so that we are able to express ' $\mu$ ' in terms of $L, M$ and $T$, the dimensional expressions can then be readily reduced to these three fundamentals; but in the meantime let us be honest with ourselves and not pretend to knowledge that we do not possess.

In Appendix VI Dr. Lanchester attempts to obtain light on the subject by calling in relativity, but seeing that it leads him to the conclusion that "a wave generated by a static charge undergoing acceleration will, in free space, be a wave having only magnetic characteristics, but which when arrested will revert to the static form", whereas "radiation from a magnetic pole or doublet would be wholly static in its manifestations until received and brought to rest", I am forced to conclude that in his search for light Dr. Lanchester has wandered into the outer darkness. In my opinion the author was unwise to include this section in a book the avowed object of which is to help the young engineer.

\title{
Gmelin's Inorganic Chemistry
}

Gmelins Handbuch der anorganischen Chemie Achte Auflage. Herausgegeben von der Deutschen Chemischen Gesellschaft.

(1) System-Nummer 4 : Stickstoff. Lief. 2. Pp. 283-506. 35 gold marks.

(2) System-Nummer 4: Stickstoff. Lief. 3. Pp. 507-854. 55 gold marks.

(3) System-Nummer 4: Stickstoff. Lief. 4. Pp. 855-1038. 25.15 gold marks. System-Nummer 23 : Ammonium. Lief. 1. Pp. 242. 28.10 gold marks.

(4) System-Nummer 35 : Aluminium. Teil A, Lief. 3. Pp. 451-534. 14 gold marks.

(5) System-Nummer 35: Aluminium. Teil A, Lief. 4. Pp. 535-682. 24 gold marks (Ausland preis, 18 gold marks).

(6) System-Nummer 55 : Uran und Isotope, mit einem Anhang über Transurane. Pp. xviii $+x+$ 279. 46 gold marks. (Ausland preis, 34.50 gold marks.)

(Berlin : Verlag Chemie, G.m.b.H., 1935-36.)

$(1,2$ and 3) $7 \mathrm{HE}$ various hydrides and oxides of matter of parts 2 and 3 of the volume on nitrogen, but aqueous solutions of ammonia and the oxyacids are not included. Prominence is given to the preparation of the raw materials used in the industrial synthesis of ammonia. It is pointed out that nitrogen extracted from air is very much cheaper than hydrogen, which comes chiefly from water-gas (51.8 per cent), coke-oven gas (30 per cent) and electrolytic plants (16.67 per cent). The Linde, Claude and Messer processes for extracting hydrogen from coke-oven gas are given very fully, as well as the synthesis of ammonia by the Haber-Bosch, Claude, Fauser and Mont Cenis methods. There is also an account of heavy ammonia, $\mathrm{ND}_{3}$, which has been obtained pure by the action of deuterium oxide on magnesium nitride.

The action of different types of electric discharge upon air and other mixtures of oxygen and nitrogen is fully discussed, but the well-known processes of Birkeland-Eyde and Pauling are not described, since it is reported that they have been largely superseded and indeed contribute at present less than one half per cent of the world's production of synthetic fixed nitrogen. There is, however, a long list of publications upon the processes.

The fourth section of the volume on nitrogen contains an account of the oxyacids and their derivatives. It is stated that nitrous acid is still unknown in the free state, but its importance has attracted the attention of many investigators. Of the three possible structural formulæ, that one 
which has a semi-polar double bond is supported by evidence derived from the parachor. Among less familiar substances described are the somewhat evanescent compound nitroxyl, $\mathrm{NOH}$, which polymerizes to hyponitrous acid, and pernitrous acid, $\mathrm{O}: \mathrm{N} . \mathrm{O} . \mathrm{OH}$, an isomer of nitric acid, arising from the interaction of hydrogen peroxide and sodium nitrite.

Compounds of the radical ammonium are so numerous and important that a whole volume has been devoted to its consideration. Sir Humphry Davy was the first to use the term ammonium and to point out its metallic properties, in particular its power of forming an amalgam, although the free radical is not yet known. That the ion has a tetrahedral structure was deduced by W. H. Mills from the optical activity of its quaternary salts. The present issue (Lief. 1) contains a full account of investigations of the system $\mathrm{NH}_{3}: \mathrm{H}_{2} \mathrm{O}$ and of the difficult problems connected with the basicity of ammonia. The extensive use of ammonium nitrate as an important constituent of high explosives was responsible for much work upon the properties of this polymorphic salt, a useful summary of which has been included.

(4 and 5). The production of special surface coatings to aluminium has become so important industrially that a whole part $(A 3)$ is devoted to it, while numerous alloys of aluminium are described in another part $(A 4)$. Both metals and non-metals are used for surfacing the metal, but whereas the former are chiefly used for decorative effects, the latter are mainly protective and greatly increase the usefulness of aluminium. Of particular interest is the electrochemical oxidation of the surface, the chief electrolytes used being chromic acid (in England), oxalic acid (in Germany and Japan) and sulphuric acid (in America). The last-named process is particularly adapted to the application of organic dyes to the oxide layer.

Alloys of aluminium have also attracted the attention of research workers in recent years to such an extent that some deviation from the general plan of the handbook has been adopted in order to collect together all those alloys which contain more than 50 per cent of aluminium. Special attention is given to alloys with silicon, which mixes with aluminium in all proportions in the liquid state, a simple eutectic system resulting on solidifying. The texture of the valuable eutectic alloy can be greatly improved by the addition of sodium or sodium fluoride.

(6) The technical uses of uranium are still very small in comparison with the amount of material rendered available as by-products in the extraction of radium. Uranium is used as a catalyst in the synthesis of ammonia, in the manufacture of steel, glass and ceramics and in dyeing and photography. A summary is given of the investigation of its isotopes, particularly of actino-uranium, with a probable atomic mass of 235 , and of the synthetic radio elements beyond uranium.

\section{Mohammedan Marriage Customs}

Marriage Conditions in a Palestinian Village By Dr. Hilma Granqvist. Vol. 1. Pp. vi +200. 75 Fmk. Vol. 2. (Societas Scientiärum Fennica : Commentationes Humanarum Litterarum, III, 8 and VI, 8.) Pp. 366. 160 Fmk. (Helsingfors: Akademische Buchhandlung; Leipzig : Otto Harrassowitz, 1931, 1936.)

$\mathrm{D}^{\mathrm{n}}$ R. HILMA GRANQVIST'S book is important both from a methodical point of view and on account of facts recorded in it. Her field studies were restricted to the village of Artās, situated south of Bethlehem at the edge of the Judaean desert and inhabited by Mohammedan Arabs. She examined all the information she was able to obtain regarding the marriages that had been contracted in the village during a period of a hundred years-in all, 264 marriages entered into by 199 men-and also procured information concerning a smaller number of marriages contracted by Artās women with men in other places. On the basis of her family lists she worked out statistics and compiled tables which formed a complement to the genealogical trees, and round this foundation the rest of her material was grouped.

This method has no doubt obvious advantages. The author writes: "In registering and discussing all the people in the village during four to five generations, we came upon a great many facts which would probably not otherwise have come to light, and the material appeared quite naturally, without having to be suggested in any way." On the other hand, it is a drawback that the genealogical method can be applied only to very limited areas, and it must also be admitted that it has not proved to be a key to so many doors as it has sometimes been supposed to unlock. Dr. Granqvist has widened the outlook by quoting numerous parallels or contrasts, remarks and references, found in printed sources relating both to Palestine and to 